\title{
Analysis of vertically loaded jet-grout-pile-strengthened piles of expanded cross-section
}

\section{Lian Wei Ren BEng, PhD}

Associate Professor, School of Civil Engineering, Henan Polytechnic University, Jiaozuo, China (corresponding author: renhpu@163.com)

Wei Dong Guo BEng, PhD, MASCE

Associate Professor, School of Civil, Mining \& Environmental Engineering, University of Wollongong, NSW, Australia

\section{Yue Bao Deng BEng, PhD}

Lecturer, Institute of Geotechnical Engineering, Ningbo University, Ningbo, China

Piles are often installed together with jet grouting - to form a jet-grout-pile-strengthened pile - in soft subsoil regions of China to increase bearing capacity and reduce project costs. To facilitate their design, this paper presents a load-transfer approach to model the non-linear behaviour of such piles with expanded cross-sections. Three interface models are introduced to describe the interactions between soil-cement, the core pile and natural soil. Force equilibrium and displacement compatibility expressions are established and implemented through a purposely designed spreadsheet. The approach was verified by loading tests on two well-instrumented piles. A parametric study shows that having one to three segments of thick soil-cement enables a $20-60 \%$ gain in bearing capacity and a 43-55\% reduction in head settlement compared with the core pile itself, which is slightly affected by the soil-cement modulus and stiffness ratio. It is cost-effective in practice to adopt two to four segments of soil-cement with a thickness of $\mathbf{0 . 1} \mathrm{m}$ to a radius of core pile, an ultimate compressive strength of the soil-cement of over $2 \mathrm{MPa}$ and a stiffness ratio of over 100 to reduce settlement. Finally, a simple equation is proposed to estimate the ultimate bearing capacity of such piles, which was verified by loading tests on piles in three case histories.

\section{Notation}

$A_{\mathrm{c}} \quad$ cross-sectional area of core pile

$A_{\mathrm{x}} \quad$ cross-sectional area of soil-cement annulus

$c \quad$ cohesion of soil around pile

$E_{\mathrm{c}} \quad$ Young's modulus of core pile

$E_{\mathrm{x}} \quad$ Young's modulus of soil-cement

$G \quad$ shear modulus of soil

$G_{\mathrm{b}} \quad$ shear modulus just beneath level of pile base

$H \quad$ depth to underlying rigid layer

$i \quad$ step number of core pile head load

$\{\mathbf{K}\} \quad$ symmetric matrix of coefficients

$k_{\mathrm{c}} \quad$ shearing rigidity of first (core pile and soil-cement (PC)) interface

$k_{\mathrm{c} m} \quad$ shearing rigidity of segment $m$ for the first (PC) interface

$k_{\mathrm{t}} \quad$ ratio of increased load to increased settlement at pile head

$k_{\mathrm{x}} \quad$ shearing rigidity of second (core pile and soil (PS)) interface

$k_{\mathrm{x} m} \quad$ shearing rigidity of segment $m$ for second (PS) interface

$k_{1} \quad$ compressive rigidity of core pile or soil-cement base soil in the first stage

$k_{2}$

$L$
$L_{\mathrm{s}}$

$L_{\mathrm{s}}$

$L_{\mathrm{x}}$

$l_{\mathrm{c}}$

$l_{\mathrm{x}}$ pile length length of soil-cement segment total length of jet grouting soil-cement length of core pile length of jet grouting soil-cement pile levels of pile head load (divided by $\Delta P$ ) $m$ th segment of core pile or soil-cement levels of pile head load after ultimate bearing capacity (divided by $0 \cdot 5 \Delta P$ )

number of core pile segments

pile head load

pile base load

ultimate bearing capacity of core pile

total base resistance

total shaft resistance

shaft resistance from PC interface

ultimate bearing capacity of jet-grout-pile-strengthened pile (JPP)

shaft resistance from PS interface

calculated load

total applied load

ultimate shaft friction of precast pile ultimate base pressure of precast pile

unconfined compressive strength

core pile base resistance

soil-cement pile base resistance

radius of core pile

radius of soil-cement pile

pile radius

base settlement related to ultimate base resistance in the first stage

$t \quad$ thickness of soil-cement

$U_{m} \quad$ compressive displacement of segment $m$ of core pile

$U_{\mathrm{n}} \quad$ compressive displacement of core pile base

$U_{0} \quad$ compressive displacement of core pile head 
$\Delta P_{\mathrm{c}}$

\section{Introduction}

High-pressure jet grouting is used to stabilise weak, soft subsoil before a conventional solid or pipe pile (simply referred to as a 'core pile' in this paper unless necessary) is 'pressed' into the soil (Ren et al., 2008). This forms a jet-grout-pilestrengthened pile (JPP) - a composite of a core pile within a jet-grouted soil-cement pile. The bond between the core pile (e.g. prestressed concrete) and the soil-cement pile allows an ultimate bearing capacity twice that of the core pile itself and saves $30 \%$ total cost. As a result, JPPs are customarily installed in coastal, soft subsoil regions of China (e.g. Tianjin and Guangzhou) to underpin high-rise buildings, industrial plants and oil tanks.

Figure 1 shows soil-cement cores unearthed in Tianjin port and a stock of pipe piles for installing JPPs. JPPs are bonded with soil-cements in clay, soft clay and silty clay. The cement bond (see Figure 2), generally speaking, is secured to full length, the upper portion, lower portion or two to four portions along the pile. The soil-cement thickness varies between $0 \cdot 1 \mathrm{~m}$ and twice the radius of the core pile. Each of the soil-cement buttresses give additional 'end' capacity (along the JPP shaft) over the 'straight-shaft' core pile itself.

The response of a vertically loaded pile can be captured well by using, for instance, ( $a$ ) analytical methods underpinned by theoretical load-transfer models (Guo and Randolph, 1999; Lee and Xiao, 2001; Randolph and Wroth, 1979; Sheil and McCabe, 2016), (b) the $\tau-z$ curve method (Chen et al., 1994; Kraft et al., 1981; Nanda and Patra, 2014; Zhang and Zhang, 2012), (c) finite-element methods (Comodromos et al., 2009; Said et al., 2009; Sheng et al., 2005), (d) boundary-element methods (Ai and Han, 2009; Mandolini and Viggiani, 1997) and (e) a variational approach (Shen et al., 1997). Among these and other methods (not all are mentioned here), the theoretical load-transfer method has been proven to be effective and efficient for single and group piles (Cao et al., 2014; Liu et al., 2004; Ren et al., 2010; Zuo, 2008) and sufficiently flexible to accommodate soil-cement segment(s) of JPPs.

In this paper, the load-transfer model is modified to simulate a JPP by incorporating three types of interface models. New expressions for force equilibrium and displacement compatibility, and the overall stiffness matrix of the pile are generated, for which a specific program (operating in Excel) was developed to facilitate the simulation. The solution/program was compared with two well-instrumented loading tests and employed to optimise design parameters of JPPs.

\section{Technical characteristics of JPPs}

The enhanced capacity of JPPs was demonstrated in comparative full-scale loading tests conducted on a JPP, cast-in-place pile and jet-grouted soil-cement wall (with an embedment of $5 \mathrm{~m}$ and a diameter of $0.5 \mathrm{~m}$ ) at a site in Hohai University, Nanjing, China (Liu et al., 2010). The measured pile head load-settlement curves are plotted in Figure 3, which shows that the JPP attained 1.33 times the (ultimate) bearing capacity of the cast-in-place pile and 2.5 times that of the jet-grouted soil-cement pile. A JPP should have a larger (shaft) resistance (see Figure 1(b)) than a conventional cast-in-place pile. Its mobilisation is warranted by a good bond between the high-strength soil-cement and the core pile, which surpasses that of a cast-in-place pile of the same diameter.

It is sometimes difficult to drive a precast pile through deepsited, stiff silty sand or silty clay layer to meet the desired depth(s). The common solution to this problem is to use highpressure jet grouting to soften the barrier before proceeding with installation of the core pile. This pile-cement system (of JPPs) shows special features. Installation practice is 


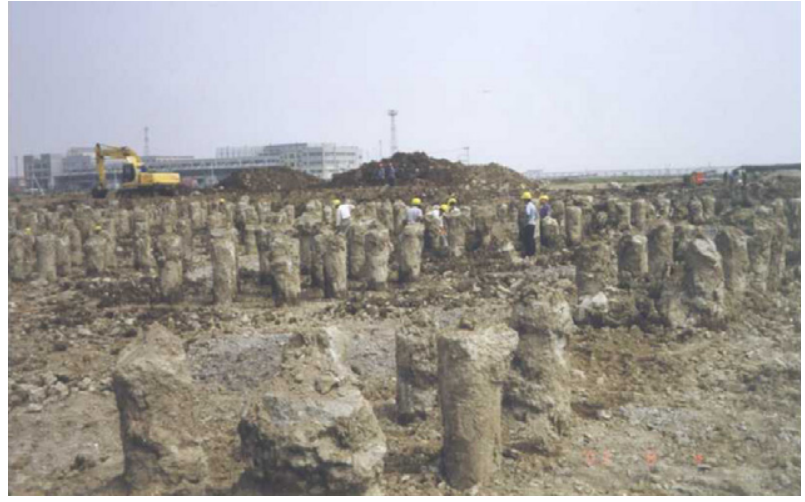

(a)

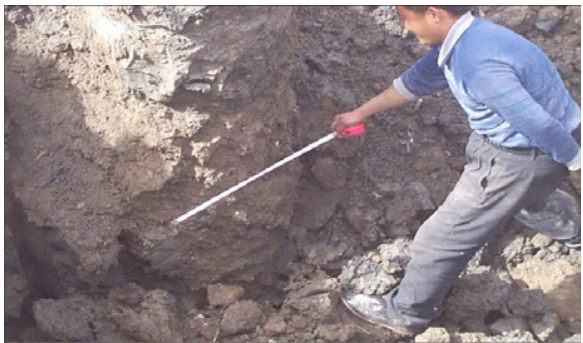

(b)

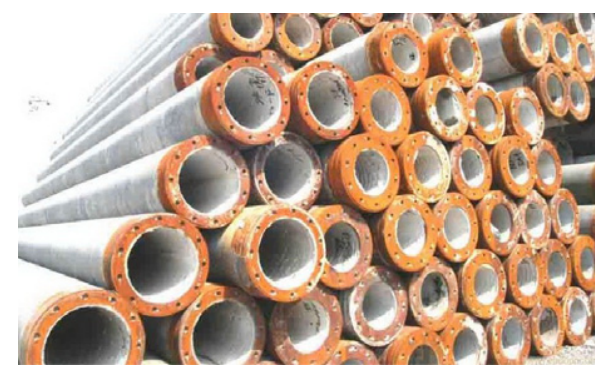

(d)

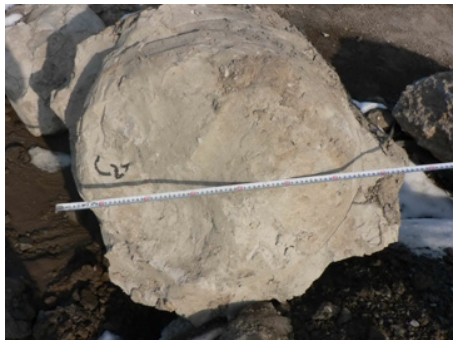

(c)

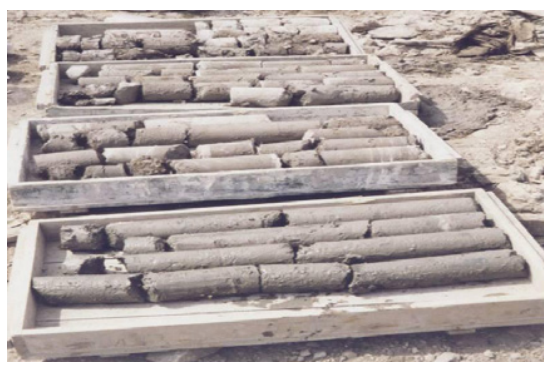

(e)

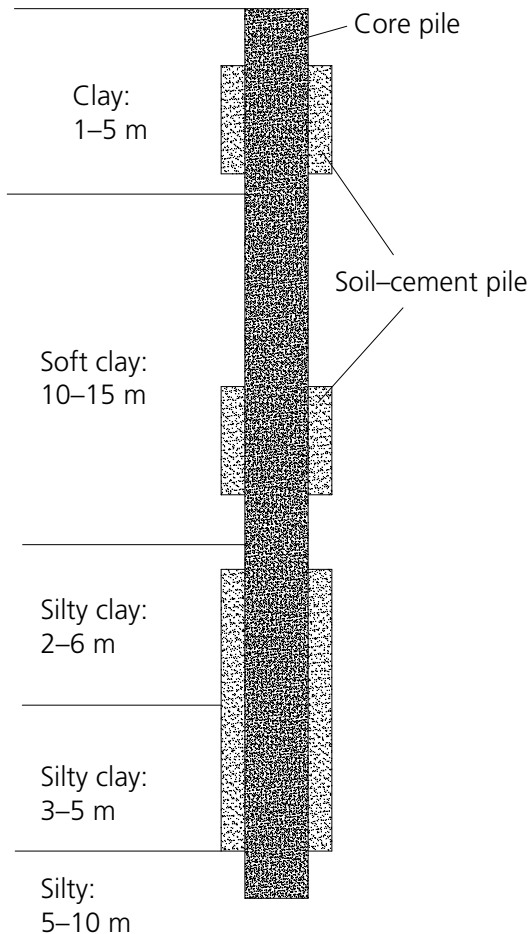

(f)

Figure 1. JPP head excavation and soil-cement corings in Tianjin port, China (Ren et al., 2008): (a) unearthed (4000) JPP pile heads; (b) in situ diameter measurement; (c) enlarged diameter measurement; (d) core (PHC) piles; (e) soil-cement cores; (f) a typical JPP in soil

recognised by $\mathrm{AB}$ and/or $\mathrm{BAB}$ construction methods: $\mathrm{A}$ denotes the use of high-pressure jetting to form soil-cement and $\mathrm{B}$ represents statically pressing down a core pile through the grouting layer to the desired depth (e.g. silt in Tianjin). As shown in Figure 4, the $\mathrm{AB}$ method comprises six steps. The $\mathrm{BAB}$ method, on the other hand, starts with pressing down a pipe pile (B) into the upper surface of a stiff layer, then installing a grouting ('drill') rod through the pipe well into the 'deep' stiff layer (below the pipe base) and jet grouting (A) to soften the stiff layer, withdrawing the drill and finally pressing the pipe pile (B) well into the softened (desired) bearing stratum (see Figure 4). A precast or prestressed high-strength concrete (PHC) pipe pile is normally utilised as the core pile to ensure good corrosion resistance (in the concerned soil) and to allow the drill rod to pass through the pipe (BAB method only) into the underlying stiff layer.

\section{Load transfer for a single JPP}

\subsection{Interface model and assumptions}

Figure 5(a) shows a vertically loaded JPP. To clarify the interfaces and interactions, the pile-cement-soil system is resolved into the core pile and the jet-grouted soil-cement wall (segment), with the pile head load $(P)$, base resistances $\left(R_{\mathrm{c}}, R_{\mathrm{x}}\right)$ and shaft shearing stresses along the pile $\left(\tau_{\mathrm{c}}\right)$ and the wall $\left(\tau_{\mathrm{x}}, \tau_{\mathrm{c}}\right)$ defined. The inside shaft stress on the cement wall is equal to the stress $\tau_{\mathrm{c}}$ on the outside surface of the core pile but in opposite directions. The system is characterised by three types of interfaces (see Figure 5(b))

a linear $\tau_{\mathrm{c}}-u$ curve for the core pile and soil-cement (first or PC) interface

- an ideal elastoplastic $\tau_{\mathrm{x}}-u$ curve for the core pile and soil (second or PS) interface and an ideal elastoplastic $\tau_{\mathrm{x}}-u$ 


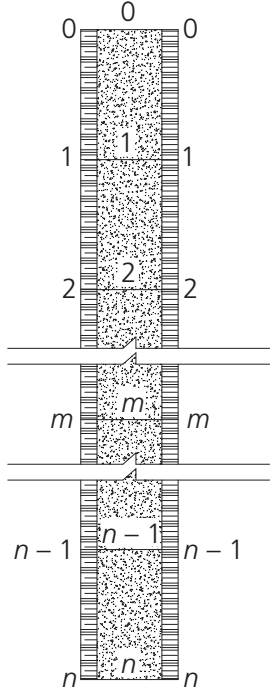

(a)

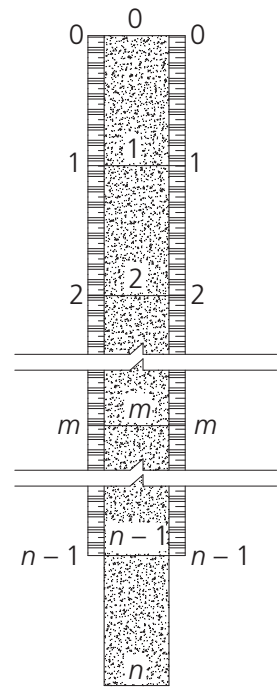

(b)

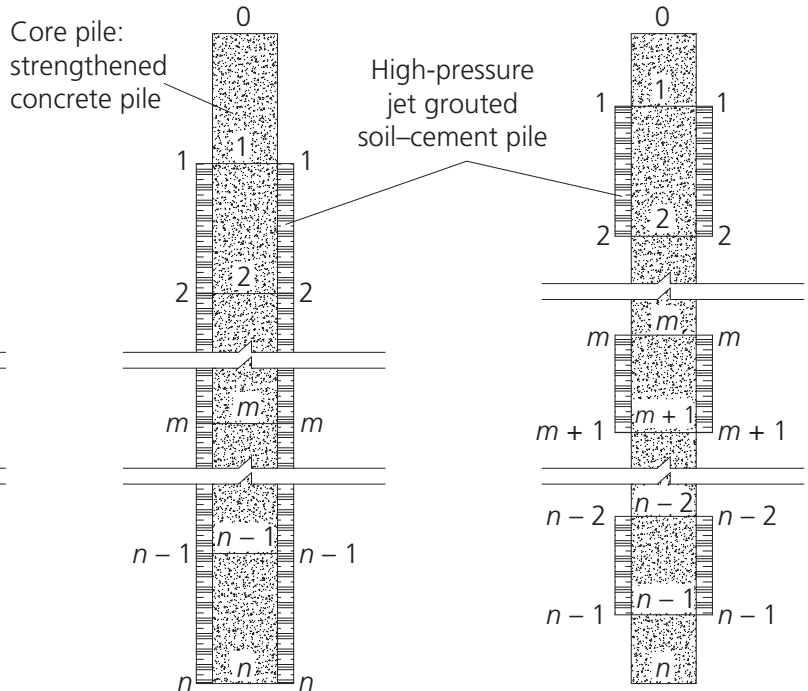

(c)

(d)

Figure 2. Common layouts and numbering rule in analysing JPPs: (a) full length; (b) upper portion; (c) lower portion; (d) segmented layout

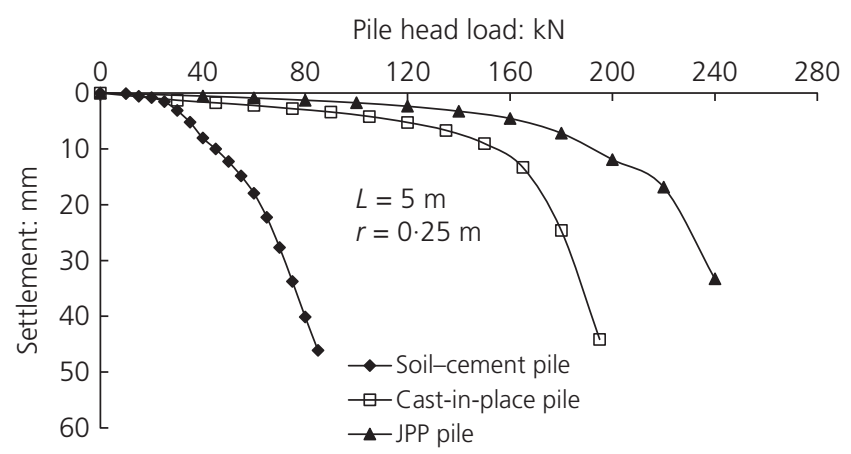

(a)

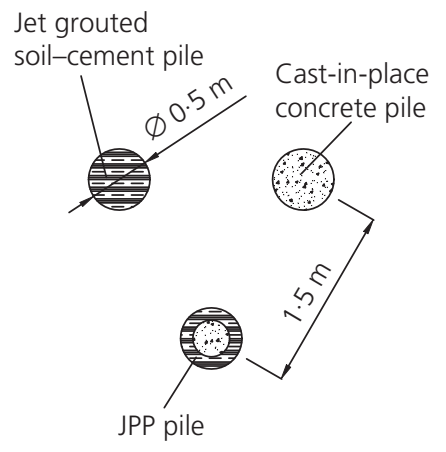

(b)

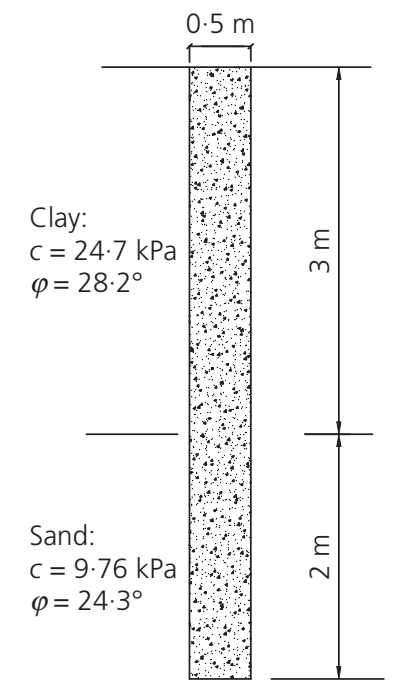

Figure 3. Measured pile head load-settlement of three piles: (a) load settlement; (b) three-pile layout curve for the soil-cement 'wall' and the soil (second or CS) interface

a bilinear relationship (described by compressive stiffness $k_{1}$ and $k_{2}$ before and after base settlement $\left(S_{\text {bu }}\right)$ ) between the base stress $\left(\tau_{\mathrm{b}}\right)$ and displacement $(S)$ at the tips of the core pile and the soil-cement.

The response of the JPP is captured by these models and the following hypotheses.

(a) The pile head load $(P)$ is exerted on the top of the core pile only, as in loading tests.

(b) The core pile or soil-cement is elastic and with a constant cross-section along the depth.

(c) The load transfer observes the three interface models.

(d) The $z$-axis is measured from the top of core pile downward.

\subsection{Load-transfer parameters of three interfaces}

\subsubsection{Shearing rigidities $k_{\mathrm{x}}$ and $k_{\mathrm{c}}$}

The shaft displacement $u$ is correlated with the local shaft stress $\tau_{\mathrm{x}}$ by (Randolph and Wroth, 1978)

1a. $u=\frac{\tau_{\mathrm{x}} r_{\mathrm{c}}}{G} \zeta$

\section{1b. $u=\frac{\tau_{\mathrm{x}} r_{\mathrm{x}}}{G} \zeta(\mathrm{CS})$}

where $r_{\mathrm{c}}$ is the radius of the core pile, $r_{\mathrm{x}}$ is the radius of the soil-cement pile, $\tau_{\mathrm{x}}$ is the shear stress on the core pile and soil 


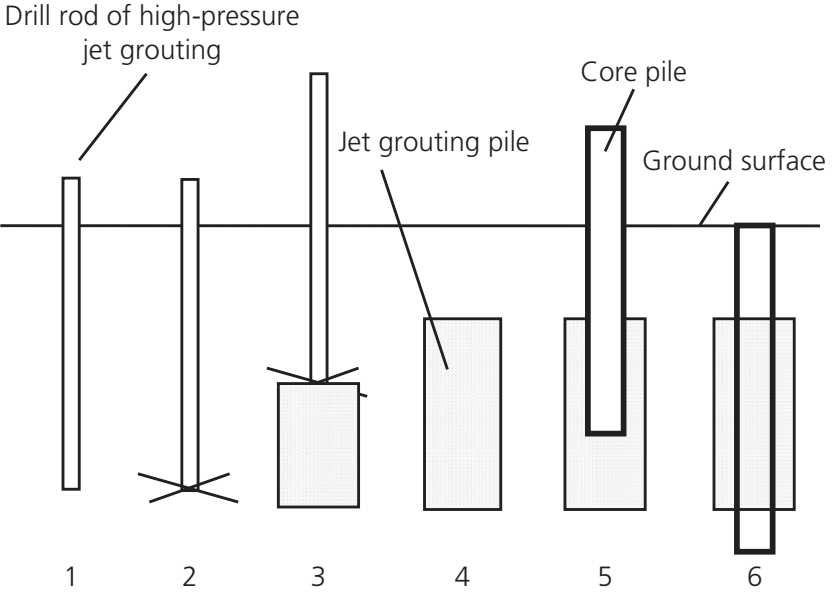

1 Press drill rod into design depth of soil

2 Jet grouting is ready

3 Soil-cement pile by jet grouting

4 Pull out drill

5 Core pile construction by static pressure

6 Press statically the core pile into design depth of bearing layer

(a)

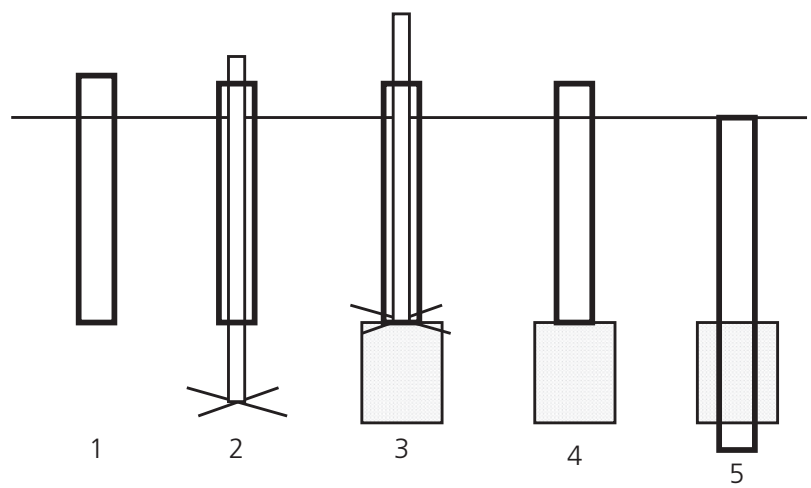

1 Press statically core pile to depth just above stiff layer

2 Press drill rod into design depth

3 Temporarily soften stiff layer soil by jet grouting

4 Pull out drill

5 Again press the core pile into design depth of bearing layer

(b)

Figure 4. JPP construction methods: (a) $A B$ method; (b) BAB method

(PS) interface or the soil-cement 'wall' and soil (CS) interface, $G$ is the soil shear modulus and $\zeta$ is a shaft load-transfer factor (Guo and Randolph, 1998) given by

2. $\zeta=\ln \left(1+1 \cdot 1 \mathrm{e}^{-\sqrt{\theta}}\left(1-\mathrm{e}^{1-(H / L)}\right)\left(\frac{1-v_{\mathrm{s}}}{1+\theta} \frac{L}{r_{\mathrm{x}}}\right)+1\right)$

where $v_{\mathrm{s}}$ is Poisson's ratio of the soil, $L$ is the length of the core pile, $\theta$ is the non-homogeneity factor, $H / L$ is the soil layer depth ratio and $H$ is the depth to the underlying rigid layer.
The factor $k_{\mathrm{x}}$ is given by

3a. $\quad k_{\mathrm{x}}=\frac{\tau_{\mathrm{xu}}}{u}=\frac{G}{r_{\mathrm{c}} \zeta}$

3b. $k_{\mathrm{x}}=\frac{\tau_{\mathrm{xu}}}{u}=\frac{G}{r_{\mathrm{x}} \zeta}$

The other factor, $k_{\mathrm{c}}$, is equal to $0 \cdot 5 q_{\mathrm{u}}\left(q_{\mathrm{u}}\right.$ is the unconfined compressive strength (UCS) of soil-cement) or $200 k_{\mathrm{x}}$ (Liu et al., 2010; Voottipruex et al., 2011).

\subsubsection{Compressive stiffness factors $k_{1}$ and $k_{2}$}

The gradients $k_{1}$ and $k_{2}$ for the bilinear correlation are determined between the base load $\left(P_{\mathrm{b}}\right)$ and base settlement $\left(u_{\mathrm{b}}\right)$. A linear relationship between base settlement and resistance (Randolph and Wroth, 1978) allows $k_{1}$ to be estimated as
4. $\quad k_{1}=\frac{P_{\mathrm{b}}}{u_{\mathrm{b}} \pi r_{0}^{2}}=\frac{4 G_{\mathrm{b}}}{\pi r_{0}\left(1-v_{\mathrm{s}}\right) \omega}$

in which $\omega$ is the base load-transfer factor and $G_{\mathrm{b}}$ is the shear modulus just beneath pile base level. The hardening factor $k_{2}$ is stipulated as (Chen et al., 1994; Zhang and Zhang, 2012)

5. $\quad k_{2}=\frac{k_{\mathrm{t}}}{1-k_{\mathrm{t}}\left(L / E_{\mathrm{c}} A_{\mathrm{c}}\right)}$

where $k_{\mathrm{t}}\left(=\Delta P / \Delta u_{\mathrm{t}}\right)$ is the ratio of the load increment $(\Delta P)$ over the pile head settlement increment $\left(\Delta u_{\mathrm{t}}\right)$ and $E_{\mathrm{c}}$ and $A_{\mathrm{c}}$ are the Young's modulus and cross-sectional area of the core pile, respectively. Note that identical $k_{1}$ and $k_{2}$ values for the core pile base are adopted for each end of the soil-cement segment.

\subsection{Load-transfer functions for a single JPP}

\subsubsection{Segment analysis of core pile and soil-cement} The JPP system is divided into $n$ segments (see Figures 5(c) and $5(\mathrm{~d}))$ and the following notation is adopted.

- $r_{\mathrm{c}}$ and $r_{\mathrm{x}}$ are the core pile radius and jet grouting soil-cement radius, respectively.

- $A_{\mathrm{c}}$ and $A_{\mathrm{x}}$ represent the section area of the core pile and the soil-cement wall, respectively.

- $E_{\mathrm{c}}$ and $E_{\mathrm{x}}$ represent the Young's modulus of the core pile and the soil-cement wall, respectively.

- $u_{m}$ and $U_{m}$ are the soil-cement displacement and the core pile displacement of segment $m$, respectively.

- $u_{0}$ and $U_{0}$ are the soil-cement head settlement and the core pile head settlement, respectively. 


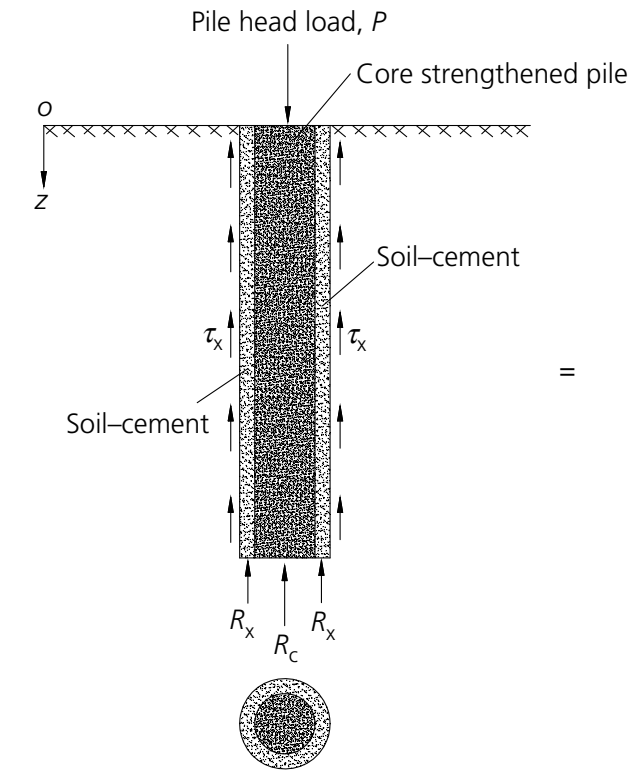

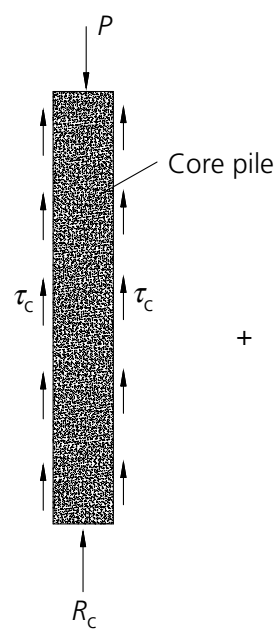

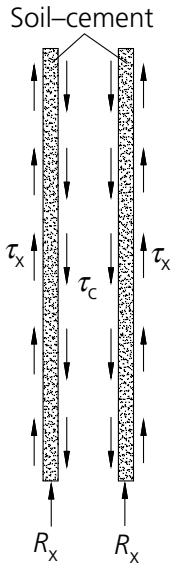

(a)
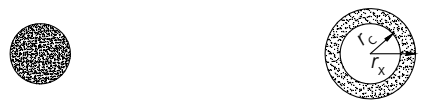

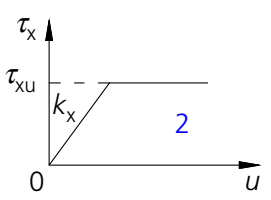

Second interface: ideal elastoplastic model

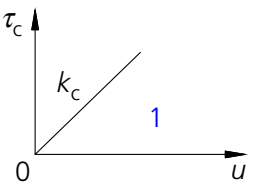

First interface: linear model

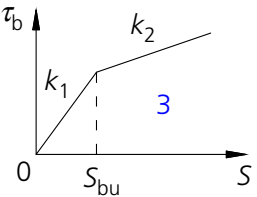

Pile base:

bilinear hardening model

(b)

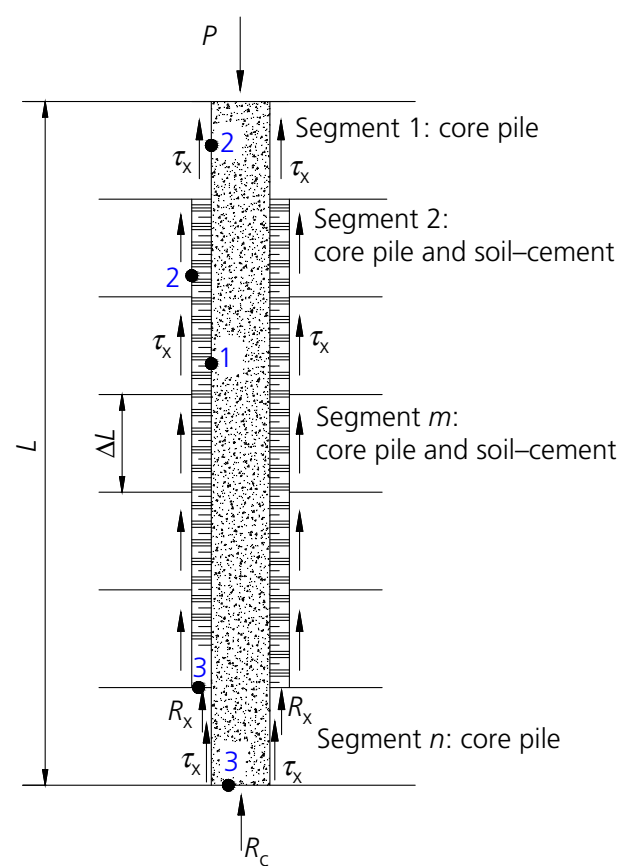

(c)

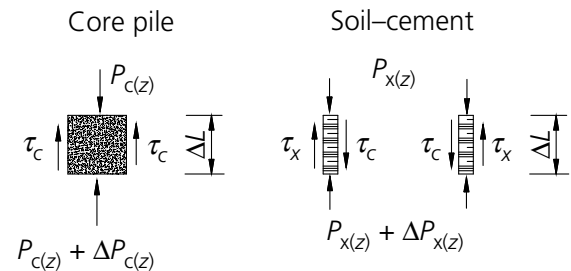

Segment $m$
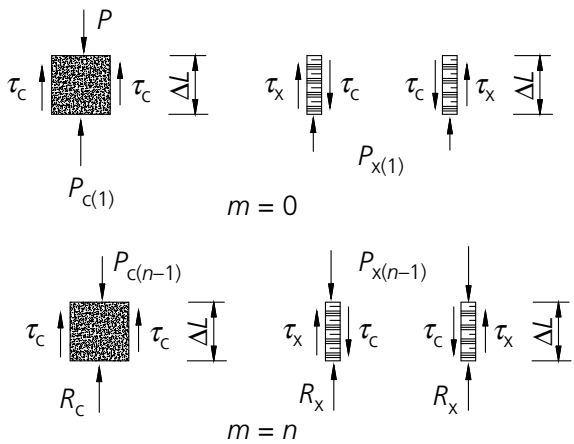

(3)

(d)

Figure 5. Load-transfer analysis of single JPP embedded in multi-layered soil: (a) core pile and soil-cement; (b) load-transfer models for three interfaces; (c) load transfer along JPP; (d) force equilibrium in typical segments

$u_{\mathrm{n}}$ and $U_{\mathrm{n}}$ are the soil-cement base settlement and the core pile base settlement, respectively.

- $k_{\mathrm{x}}$ and $k_{\mathrm{c}}$ are the shearing rigidities between the soil-cement or core pile and soil around the JPP, and between the core pile and the soil-cement, respectively.

- $k_{1}$ and $k_{2}$ are the compressive rigidities of the soil below the core pile and the soil-cement base in the first and second stages of the load-displacement curve, respectively.
$S_{\text {bu }}$ is the core pile and soil-cement base settlement related to the ultimate base resistance in the first stage.

The shaft resistances $Q_{\mathrm{sc}}$ (from the PC interface) and $Q_{\mathrm{x}}$ (from the PS interface) under $\tau_{\mathrm{x}}<\tau_{\mathrm{xu}}$ (limiting shearing stress of the PS interface) are estimated as

6. $Q_{\mathrm{sc}}=2 \pi r_{\mathrm{c}} \Delta L k_{\mathrm{c} m}\left(U_{m}-u_{m}\right) \leq 2 \pi r_{\mathrm{c}} \Delta L \tau_{\mathrm{cu}}$ 


\section{7. $Q_{\mathrm{x}}=2 \pi r_{\mathrm{x}} \Delta L k_{\mathrm{x} m} u_{m} \leq 2 \pi r_{\mathrm{x}} \Delta L \tau_{\mathrm{xu}}$}

where $k_{\mathrm{c} m}$ and $k_{\mathrm{x} m}$ are the shearing stiffnesses (of segment $m$ ) for the first (PC) and the second (PS) interfaces, respectively and $\Delta L$ is the length of pile segment $m$. The base resistance of the core pile $\left(R_{\mathrm{c}}\right)$ is linearly related to $U_{\mathrm{n}}$ (core) by Equation 8 with a different gradient from the turning point $S_{\text {bu }}$ (ultimate base settlement) onwards. The soil-cement resistance $\left(R_{\mathrm{x}}\right)$ is linearly related to $u_{\mathrm{n}}$ by Equation 9 .

8a. $\quad R_{\mathrm{c}}=A_{\mathrm{c}} k_{1} U_{\mathrm{n}}\left(U_{\mathrm{n}}<S_{\mathrm{bu}}\right)$

8b. $\quad R_{\mathrm{c}}=A_{\mathrm{c}} k_{2} U_{\mathrm{n}}+A_{\mathrm{c}}\left(k_{1}-k_{2}\right) S_{\mathrm{bu}}\left(U_{\mathrm{n}} \geq S_{\mathrm{bu}}\right)$

9a. $\quad R_{\mathrm{x}}=A_{\mathrm{x}} k_{1} u_{\mathrm{n}} \quad\left(u_{\mathrm{n}}<S_{\mathrm{bu}}\right)$

9b. $\quad R_{\mathrm{x}}=A_{\mathrm{x}} k_{2} u_{\mathrm{n}}+A_{\mathrm{x}}\left(k_{1}-k_{2}\right) S_{\mathrm{bu}} \quad\left(u_{\mathrm{n}} \geq S_{\mathrm{bu}}\right)$

Incremental axial forces on segment $m$ of the core pile $\left(\Delta N_{m}\right)$ and the soil-cement $\left(\Delta n_{m}\right)$ are given by

10. $\Delta N_{m}=B_{m}\left(\Delta U_{m-1}-\Delta U_{m}\right)$ with $B_{m}=A_{\mathrm{c}} E_{\mathrm{c}} / \Delta L$

11. $\Delta n_{m}=b_{m}\left(\Delta u_{m-1}-\Delta u_{m}\right)$ with $b_{m}=A_{\mathrm{x}} E_{\mathrm{x}} / \Delta L$

\subsubsection{Load-transfer matrix for pile-soil system}

The JPP consists of combined segments (soil-cement and core pile) and the core-pile-only segment. The current analysis adopts the numbering shown in Figure 2. The equilibrium of axial force and displacement compatibility allow development of expressions (T1) to (T14) as summarised in Table 1. The expressions allow the load-settlement relationship for the JPP to be written as

12. $\{\mathbf{K}\}\{\Delta \mathbf{U}\}=\{\Delta \mathbf{F}\}$

where $\{\boldsymbol{\Delta} \mathbf{U}\}$ is the displacement increment matrix of the core pile and soil-cement, $\{\mathbf{K}\}$ is the symmetric coefficient matrix of $2(n+1) \times 2(n+1)$ for full length, $\left(n+n_{1}+2\right) \times\left(n+n_{1}+2\right)$ for upper or lower portion, $\left[n+1+N\left(n_{2}+1\right)\right] \times\left[n+1+N\left(n_{2}+1\right)\right]$ for a segmented layout, in which $n$ is the segment number of the core pile, $n_{1}$ is the segment number of the soil-cement, $N$ is the number of soil-cement wall for segment layout and $n_{2}$ is the segment number of each soil-cement wall for segment layout.

$$
\text { 13. }\{\Delta \mathrm{Y}\}^{\mathrm{T}}=\left\{\Delta U_{0}, \Delta u_{0}, \Delta U_{1}, \Delta u_{1}, \ldots, \ldots, \Delta U_{n}, \Delta u_{n}\right\}
$$

14. $\{\Delta \mathbf{F}\}^{\mathrm{T}}=\{\Delta P, 0,0, \ldots, 0\}$

Soil-cement settlements $\Delta u_{m}$ of the core-pile-only segment are removed from the matrix $\{\Delta \mathbf{U}\}$.

\subsubsection{Algorithm for calculation of a single JPP in layered soils}

A single JPP in a multi-layered soil is modelled in the following nine steps.

(a) Divide the core pile into $n$ segments, each with length $\Delta L(=L / n)$, as is adopted for each segment of the soil-cement. The length $\Delta L$ thus needs to suit the thickness of each soil layer and the length of the soil-cement. The load $P$ is divided into $M$ levels $(\Delta P=P / M)$, with a first step $i(=1)$. Note, to improve accuracy, the loading rate is reduced into $0 \cdot 5 \Delta P$ ( $N$ levels) as the total load $P$ approaches the ultimate

Table 1. Equations of the simplified method for JPPs

\begin{tabular}{|c|c|c|}
\hline & Core pile & Soil-cement pile \\
\hline Combined & $\begin{array}{l}-\left(B_{1}+D_{0}\right) \Delta U_{0}+D_{0} \Delta u_{0}+B_{1} \Delta U_{1}=-\Delta P(m=0)(\mathrm{T} 1) \\
\quad B_{m} \Delta U_{m-1}-\left(B_{m}+B_{m+1}+D_{m}\right) \Delta U_{m}+D_{m} \Delta u_{m} \\
+B_{m+1} \Delta U_{m+1}=0(\mathrm{~T} 2) \\
\quad \text { where } D_{m}=2 \pi r_{\mathrm{c}} \Delta L k_{\mathrm{cm}}(\mathrm{T} 3) \\
\quad B_{n} \Delta U_{n-1}-\left(B_{n}+D_{n}+D_{c}\right) \Delta U_{n}+D_{n} \Delta u_{n}=0(m=n)(\mathrm{T} 4) \\
\text { where } D_{c}=A_{c} k_{1}\left(U_{n} \leq S_{\mathrm{bu}}\right) \text { or } D_{\mathrm{c}}=A_{c} k_{2}\left(U_{n}>S_{\mathrm{bu}}\right)(\mathrm{T} 5)\end{array}$ & $\begin{array}{l}D_{0} \Delta U_{0}-\left(b_{1}+d_{0}+D_{0}\right) \Delta u_{0}+b_{1} \Delta u_{1}=0(m=0)^{\mathrm{a}}(\mathrm{T} 10) \\
\quad b_{m} \Delta u_{m-1}+D_{m} \Delta U_{m}-\left(b_{m}+b_{m+1}+d_{m}+D_{m}\right) \Delta u_{m} \\
+b_{m+1} \Delta u_{m+1}=0(\mathrm{~T} 11) \\
\text { where } d_{m}=2 \pi r_{x} \Delta L k_{\mathrm{x} m}(\mathrm{~T} 12) \\
b_{n} \Delta u_{n-1}+D_{n} \Delta U_{n}-\left(b_{n}+d_{n}+D_{n}+d_{x}\right) \Delta u_{n}=0(m=n)^{\mathrm{a}}(\mathrm{T} 13) \\
\text { where } d_{x}=A_{x} k_{1}\left(u_{n} \leq S_{\mathrm{bu}}\right) \text { or } d_{\mathrm{x}}=A_{x} k_{2}\left(u_{n}>S_{\mathrm{bu}}\right)(\mathrm{T} 14)\end{array}$ \\
\hline Core pile only & $\begin{array}{l}-\left(B_{1}+D_{0}\right) \Delta U_{0}+B_{1} \Delta U_{1}=-\Delta P(m=n)(\mathrm{T} 6) \\
\quad B_{m} \Delta U_{m-1}-\left(B_{m}+B_{m+1}+D_{m}\right) \Delta U_{m}+B_{m+1} \Delta U_{m+1}=0(\mathrm{~T} 7) \\
\quad \text { where } D_{m}=2 \pi r_{c} \Delta L k_{\mathrm{x} m}(\mathrm{~T} 8) \\
\quad B_{n} \Delta U_{n-1}-\left(B_{n}+D_{n}+D_{c}\right) \Delta U_{n}=0(m=n)(\mathrm{T} 9)\end{array}$ & \\
\hline
\end{tabular}

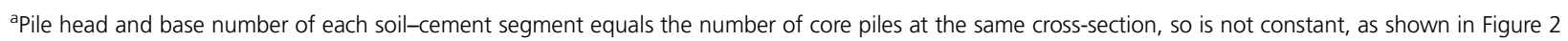




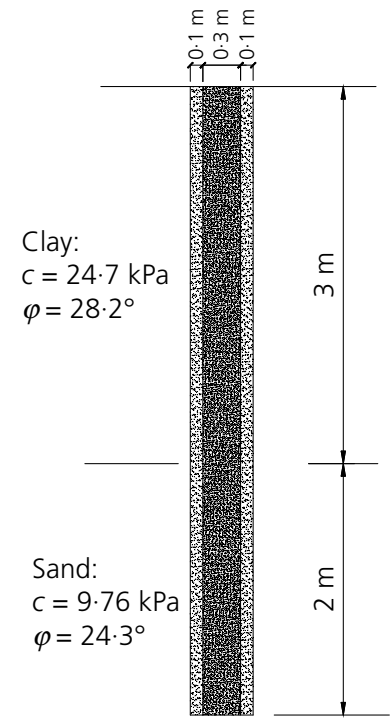

(a)

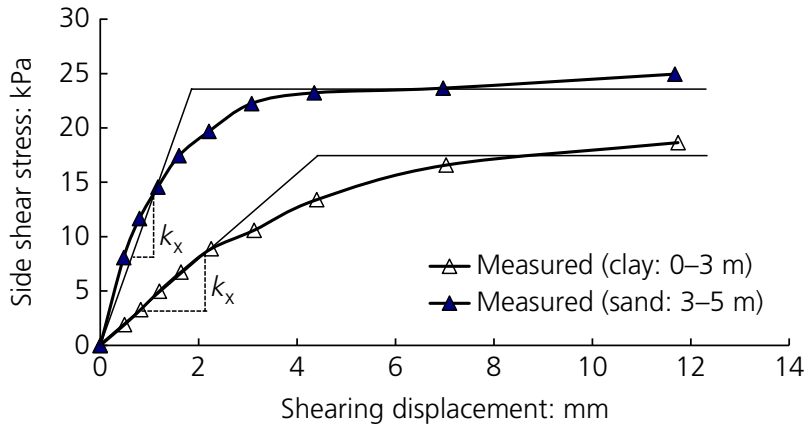

(b)

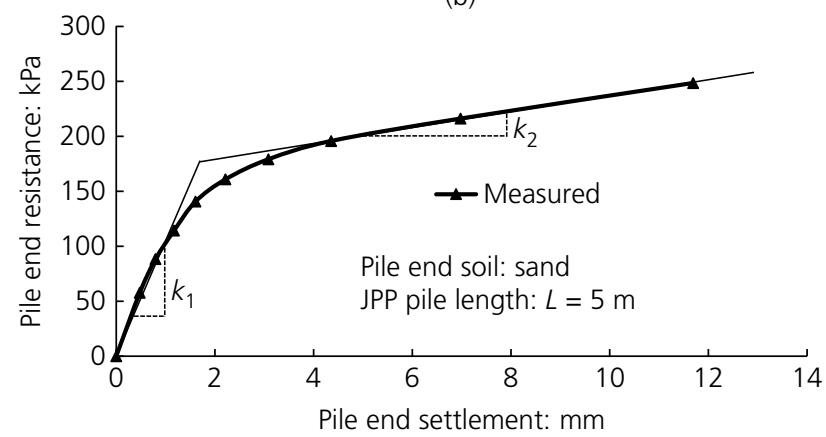

(c)

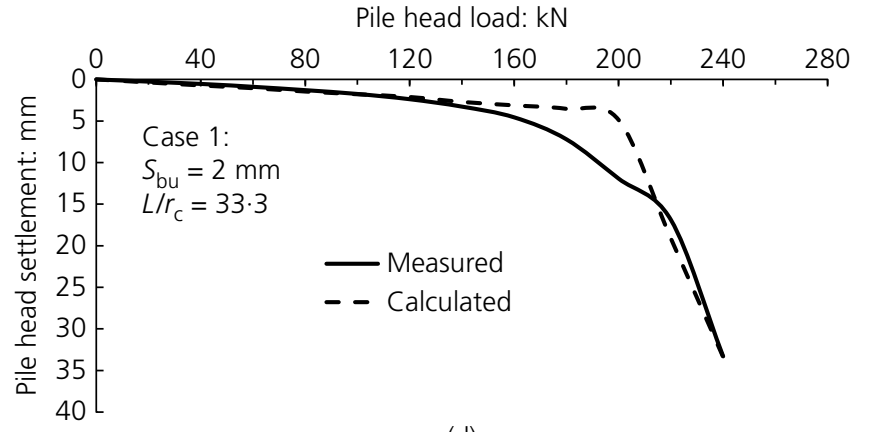

(d)

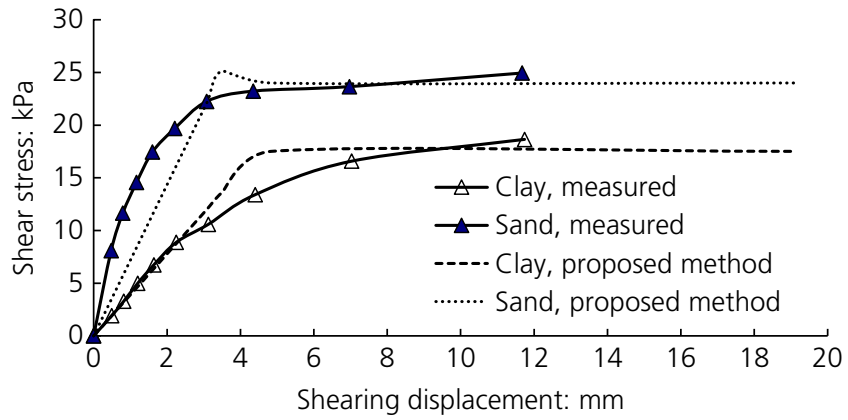

(f)

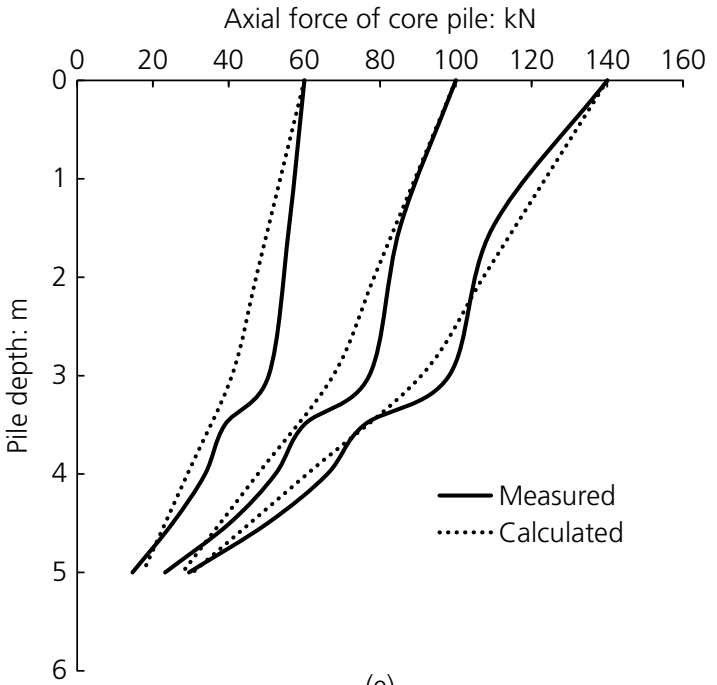

(e)

Figure 6. Full-scale loading test on a JPP (case 1): (a) pile and soil system; (b) shaft resistance-displacement curves; (c) base resistance-settlement curve; (d) head load-settlement curves; (e) axial force distributions; (f) local shear stress-displacement curves

level (the second (PS) interface rigidity $k_{\mathrm{x}}$ of every layer soil are almost all zero).

(b) Calculate the parameters $B_{m}, b_{m}, D_{m}, d_{m}, D_{\mathrm{c}}$ and $d_{\mathrm{x}}$ using Equations 10 and 11, and Equations (T3), (T8), (T12), (T5) and (T14) (in Table 1), respectively. (c) Calculating each element in the symmetric matrix using Equations (T1), (T2), (T4), (T6), (T7), (T9), (T10), (T11) and (T13) (in Table 1) and form the matrix $\{\mathbf{K}\}$.

(d) Solve Equation 12 to gain elastic deformation increments of the core pile and soil-cement segments at the $i$ th $\Delta P$. 
Table 2. Physical and mechanical parameters of soil in full-scale tests (Liu et al., 2010)

\begin{tabular}{lccccc} 
Soil & Water content: \% & Density: $\mathbf{k N} / \mathbf{m}^{\mathbf{3}}$ & Cohesion: $\mathbf{k P a}$ & Friction angle: degrees & Compression modulus, $\boldsymbol{E}_{\mathbf{s}}: \mathbf{M P a}$ \\
\hline Clay & $29 \cdot 3$ & $19 \cdot 2$ & 24.70 & 28.2 & 4.69 \\
Sand & 5.49 & $15 \cdot 5$ & 9.76 & $24 \cdot 3$ & 14.70
\end{tabular}

Table 3. Parameters for load-transfer model (case 1)

\begin{tabular}{lccccccc} 
Soil & Thickness: $\mathbf{m}$ & $\boldsymbol{k}_{\mathbf{c}}: \mathbf{M P a} / \mathbf{m}$ & $\boldsymbol{k}_{\mathbf{x}}: \mathbf{M P a} / \mathbf{m}$ & $\boldsymbol{k}_{\mathbf{1}}: \mathbf{M P a} / \mathbf{m}$ & $\boldsymbol{k}_{\mathbf{2}}: \mathbf{M P a} / \mathbf{m}$ & $\boldsymbol{\tau}_{\mathbf{x u}}: \mathbf{k P a}$ & $\boldsymbol{S}_{\text {bu: }}: \mathbf{m m}$ \\
\hline Clay & 3.0 & 778 & 3.89 & 7.17 & 72.53 & - & 17.51 \\
Sand & 3.5 & 1434 & 7.15 & 24.00 & 2
\end{tabular}

Table 4. Comparison of calculated and measured parameters for load-transfer model

\begin{tabular}{|c|c|c|c|c|c|c|c|c|c|}
\hline \multirow[b]{2}{*}{ Soil } & \multirow[b]{2}{*}{ G: MPa } & \multicolumn{2}{|c|}{$k_{\mathrm{x}}: \mathrm{MPa} / \mathrm{m}$} & \multicolumn{2}{|c|}{$\zeta$} & \multicolumn{2}{|c|}{$k_{1}: \mathrm{MPa} / \mathrm{m}$} & \multicolumn{2}{|c|}{$k_{2}: \mathrm{MPa} / \mathrm{m}$} \\
\hline & & Measured & Equation 3 & Measured & Equation 2 & Measured & Equation 4 & Measured & Equation 5 \\
\hline \multicolumn{10}{|l|}{ Case $1^{a}$} \\
\hline Clay & $2 \cdot 61$ & 3.89 & 3.64 & $2 \cdot 68$ & $2 \cdot 86$ & $72 \cdot 53$ & $85 \cdot 32$ & $7 \cdot 15$ & $6 \cdot 21$ \\
\hline Sand & $5 \cdot 44$ & $7 \cdot 17$ & $7 \cdot 62$ & 3.04 & & & & & \\
\hline \multicolumn{10}{|l|}{ Case $2^{\mathrm{b}}$} \\
\hline Clay & $5 \cdot 78$ & - & 4.01 & - & $4 \cdot 12$ & - & $144 \cdot 74$ & - & $66 \cdot 41$ \\
\hline Soft clay & $3 \cdot 89$ & - & $2 \cdot 70$ & & & & & & \\
\hline Silty & $5 \cdot 56$ & - & $6 \cdot 74$ & & & & & & \\
\hline
\end{tabular}

${ }^{a}$ Case 1: $v_{\mathrm{s}}=0.35, \theta=0.5, G_{\mathrm{b}}=10.89 \mathrm{MPa}, \omega=1$

${ }^{\mathrm{b} C a s e} 2: v_{\mathrm{s}}=0.35, \theta=0.5, G_{\mathrm{b}}=14.78 \mathrm{MPa}, \omega=1$

(e) Calculate the shearing stress of the first (PC) and second (PS) interface of each segment using Equations 6 and 7, respectively, and the axial force of the core pile and soil-cement using Equations 10 and 11 , respectively.

(f) Take shearing stiffness $k_{\mathrm{x}}$ (between soil-cement or core pile and soil) as zero if the shearing stress exceeds the upper limit.

(g) Change the rigidity $k_{1}$ into $k_{2}$ at the next load step when the base settlement of the core pile or soil-cement reaches the ultimate deformation $S_{\mathrm{bu}}$.

(h) Calculate the load $Q_{1}\left(=Q_{\mathrm{s}}+Q_{\mathrm{b}}, Q_{\mathrm{s}}\right.$ is the total shaft force and $Q_{\mathrm{b}}$ is the total base resistance) and check whether $\left(Q_{2}-Q_{1}\right) / Q_{2}<0 \cdot 05$ (a specified tolerance) is valid, in which the total load is $Q_{2}(=\Delta P+\Delta P+i \ldots)$. Use $\left(Q_{2}-Q_{1}\right)$ as the new value of $\Delta P$ to repeat steps (a)-(g) until $\left(Q_{2}-Q_{1}\right) / Q_{2}$ is within the assumed tolerance. (i) $i=i+1$, if $i \leq M+N$, move to the next load step until the calculation process is complete.

The calculation results show that the proposed calculation method is simple and efficient, regardless of layered soils and variable cross-sections and layouts.

\section{Case studies}

The proposed method is exemplified by simulating single JPPs in two multi-layered soil profiles.

\subsection{Case 1: Full-length JPP in a clay-sand layer}

Liu et al. (2010) reported full-scale loading tests on a single JPP embedded in a $3 \mathrm{~m}$ clay layer underlain by a $3.5 \mathrm{~m}$ sand layer (Figure 6(a)). The physical and mechanical parameters of the subsoil are provided in Table 2. The clay/sand-cement (JPP) pile had an external radius of $0.25 \mathrm{~m}$, a wall thickness of $0.1 \mathrm{~m}\left(r_{\mathrm{x}}=0.25 \mathrm{~m}\right)$ and Young's moduli of $E_{\mathrm{xc}}=0.90 \mathrm{GPa}$ for clay-cement and $E_{\mathrm{xs}}=2 \cdot 19 \mathrm{GPa}$ for sand-cement. A PHC pipe pile $\left(0 \cdot 15 \mathrm{~m}\right.$ in external radius and $\left.E_{\mathrm{c}}=38 \mathrm{GPa}\right)$ was pressed $5 \mathrm{~m}$ down into the subsoil.

The loading tests provided the average shaft resistance $(\tau)$ relative displacement curve $(w)$, the base resistance-settlement curve, the pile head load-settlement curve of the JPP and the axial load distribution of the pipe pile; these are shown in Figures 6(b), 6(c), 6(d) and 6(e), respectively. The single JPP was divided into five segments $(m=5)$ with a segment length $(\Delta L)$ of $1.0 \mathrm{~m}$. It was modelled using the parameters shown in Table 3. The calculated load-settlement curves and the load distribution are shown in Figures 6(d) and 6(e), respectively. The slight overestimation of the ultimate bearing capacity (of $200 \mathrm{kN}$ ) is due to a similar overestimation of the shearing stress $\tau$ against the field measurement (see Figure 6(f)). The parameters $\zeta, k_{\mathrm{x}}, k_{1}$ and $k_{2}$ describing the $\tau-u$ curves agree well with the measured results (see Table 4). Equations 2-5 are thus sufficiently accurate in terms of predictions against measured data. This conclusion is further validated in the following case. 


\subsection{Case 2: Upper portion of JPP in clay-soft clay-silty} clay layer

Ren et al. (2008) conducted loading tests on a JPP 'wrapped' with soil-cement to $75 \%$ of its length from ground level (see Figure 7(a)) and provided load-displacement curves. A PHC pile $\left(E_{\mathrm{c}}=38 \mathrm{GPa}\right.$, diameter of $\left.0.4 \mathrm{~m}\right)$ was installed to a depth of $20 \mathrm{~m}$. The jet-grouted soil-cement wall was $15 \mathrm{~m}$ long, $0.7 \mathrm{~m}$ in external diameter $(0.15 \mathrm{~m}$ in wall thickness) and had an UCS of $2 \mathrm{MPa}$ (mean value, due to sufficient cement

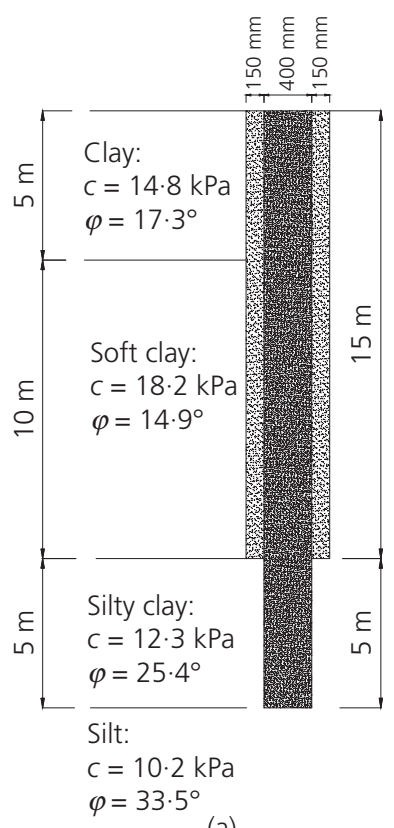

(a)

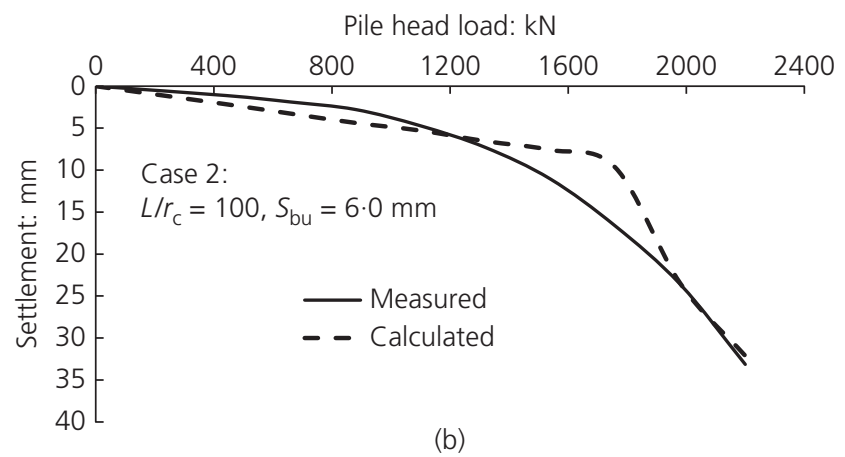

Figure 7. (a) Pile-soil system for case 2. (b) Predicted and measured pile head load-displacement curves for case 2 mixed with clay/soft clay, see Figure 7(a)). JPPs were installed in situ by the jet grouting method with a jet pressure of $23 \mathrm{MPa}$. The water/cement ratio of the cement slurry was $1 \cdot 2$ and the cement content employed for jet grouting construction was $160 \mathrm{~kg} / \mathrm{m}^{3}$ of soil.

The parameters $\zeta, k_{\mathrm{x}}, k_{1}$ and $k_{2}$ were estimated and are shown in Table 4. $S_{\text {bu }}$ was deduced from the loading test results. The subsoil was modelled as a four-layer soil system (i.e. clay, soft clay, silty clay and silt layers; see Table 5). The values of $\tau_{\mathrm{xu}}$ (as deduced from the geotechnical investigation report) were $29 \mathrm{kPa}$, $23 \mathrm{kPa}$ and $62 \mathrm{kPa}$ for the upper soil layers. The predicted load-settlement curve (see Figure 7(b)) and ultimate bearing capacity (of $1.8 \mathrm{MN}$ ) compare well with the measured data for the JPP (upper portion), despite the slight underestimation $(<1 \cdot 2 \mathrm{MN})$ or overestimation $(>1 \cdot 2 \mathrm{MN})$ of the settlement.

\section{Parametric study}

The impact of layout of segments, soil-cement thickness, soil-cement modulus $E_{\mathrm{x}}$ and stiffness ratio $k_{\mathrm{c}} / k_{\mathrm{x}}$ on the load-displacement response of a single JPP embedded in a homogenous soil is examined in this section. The hypothetical JPP is $20 \mathrm{~m}$ long and $0.6 \mathrm{~m}$ (soil-cement) and $0.4 \mathrm{~m}$ (core pile) in diameter (see Figure 8(a)). The Young's moduli are $38 \mathrm{GPa}$ for the core pile and $0.9 \mathrm{GPa}$ for the soil-cement. The limiting shaft resistance of each segment, $\tau_{\mathrm{xu}}$ (Guo and Randolph, 1997), is taken as $\tau_{\mathrm{xu}}=10 z^{0.5}$ where $z$ is the depth below the ground surface. The interface models are described by $k_{\mathrm{c}}=1000 \mathrm{MPa} / \mathrm{m}$, $k_{\mathrm{x}}=10 \mathrm{MPa} / \mathrm{m}, S_{\mathrm{bu}}=5.5 \mathrm{~mm}, k_{1}=50 \mathrm{MPa} / \mathrm{m}, k_{2}=5 \mathrm{MPa} / \mathrm{m}$.

\subsection{Layout of segments}

It is often critical to select the grouting layout for each site. As an example, a JPP in a homogenous soil were simulated concerning a full length, an upper portion, a lower portion, two segments and three segments of soil-cement (see Figure 8(a)). The total length of the soil-cement was maintained at $12 \mathrm{~m}$ in the form of either two $6 \mathrm{~m}$ length segments, three $4 \mathrm{~m}$ long segments and so on. The predicted load-settlement curves and pile head load-base load curves are shown in Figures 8(b) and 8(c), respectively. The figures indicate that three segments (also full length) of soil-cement offered the highest ultimate bearing capacity of the JPP. The capacity reduced gradually from layouts of three segments, two segments, lower portion to upper portion (the lowest). These reduction may originate from the base resistance, which exhibited a similar reduction. This

Table 5. Soil profile and parameters for load-transfer model (case 2)

\begin{tabular}{lcccccc} 
Soil & Layer thickness: $\mathbf{m}$ & Density: $\mathbf{k N} / \mathbf{m}^{\mathbf{3}}$ & Modulus, $\mathbf{E}_{\mathbf{s}}: \mathbf{M P a}$ & $\boldsymbol{k}_{\mathbf{c}}: \mathbf{M P a} / \mathbf{m}$ & $\boldsymbol{k}_{\mathbf{x}}: \mathbf{M P a} / \mathbf{m}$ & $\boldsymbol{\tau}_{\mathbf{x u}}: \mathbf{k P a}$ \\
\hline Clay & 5 & $18 \cdot 9$ & $5 \cdot 2$ & 980 & $4 \cdot 9$ & 29 \\
Soft clay & 10 & $17 \cdot 7$ & $3 \cdot 5$ & 660 & $3 \cdot 3$ & 23 \\
Silty clay & 5 & 19 & 5 & 1648 & -24 & 62 \\
Silt & 8 & $19 \cdot 8$ & $13 \cdot 3$ & - & & -
\end{tabular}




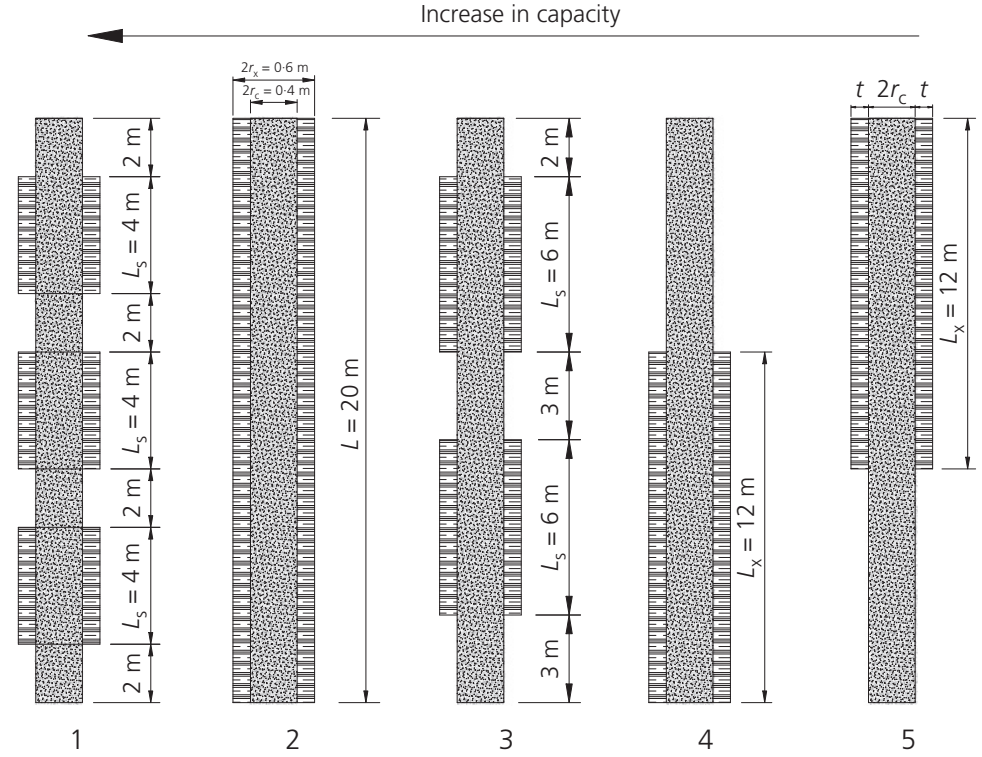

(a)

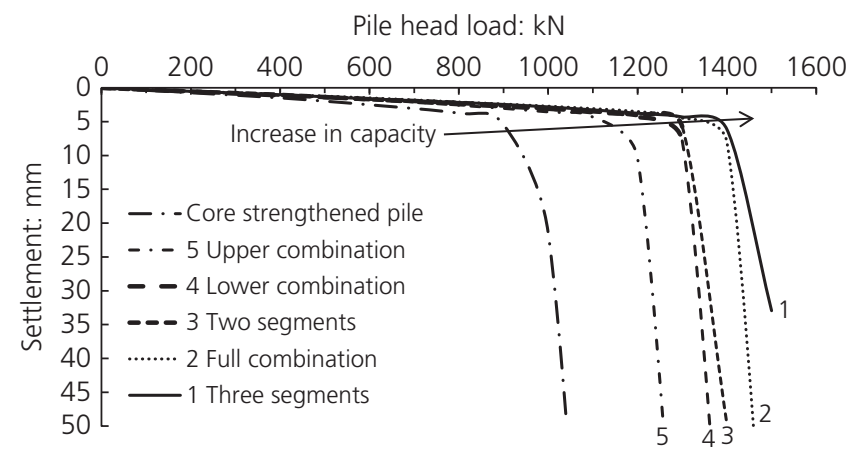

(b)

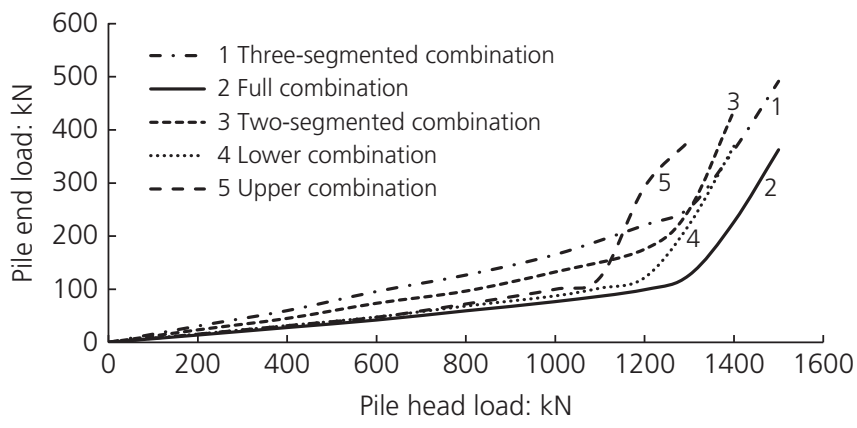

(c)

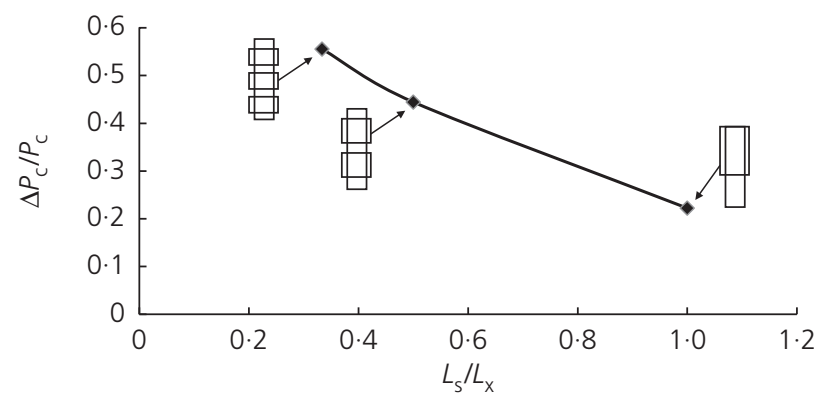

(d)

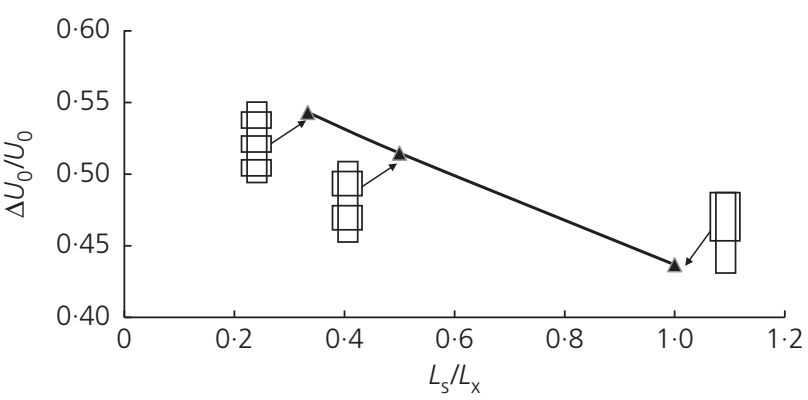

(e)

Figure 8. Soil-cement layouts for capacity and settlement: (a) five layouts; (b) pile head load-settlement curves; (c) head load-base load curves; (d) $L_{S} / L_{x}$ plotted against normalised gain in head capacity; (e) $L_{s} / L_{x}$ plotted against normalised reduction in head settlement

analysis concurs with the practice of forming two to four soilcement segments (by jet grouting) to increase bearing capacity and reduce settlement.

\subsection{Soil-cement thickness}

The soil-cement thickness 'wrapping' the core pile needs to be selected to ensure sufficient pile capacity. Taking a thickness $t\left(=r_{\mathrm{x}}-r_{\mathrm{c}}\right)$ of $0-0 \cdot 2 \mathrm{~m}\left(\right.$ or $t / r_{\mathrm{c}}=0-1 \cdot 0$, thickness normalised by the radius of the core pile), the head load-settlement and head load-base load curves were obtained for the three-segment JPP. As shown in Figures 9(a) and 9(b), an increase in thickness (and thus cross-section and shaft area) to an effective radius $r_{\mathrm{x}}\left(<10 r_{\mathrm{c}}\right.$ theoretically) increased the ultimate bearing capacity. The force equilibrium of the soil-cement unit 


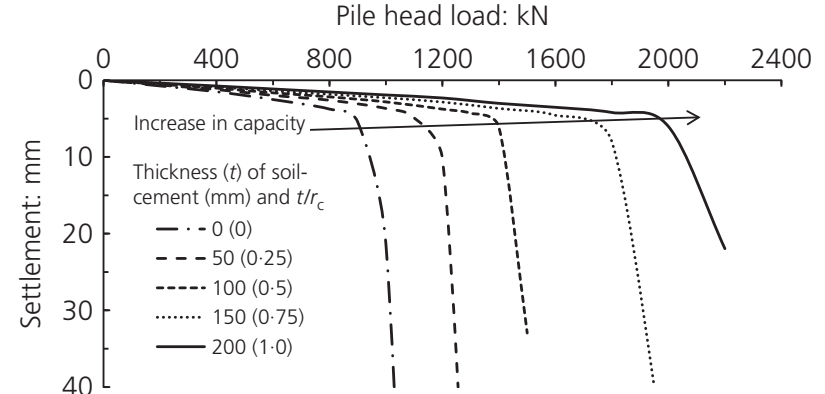

(a)

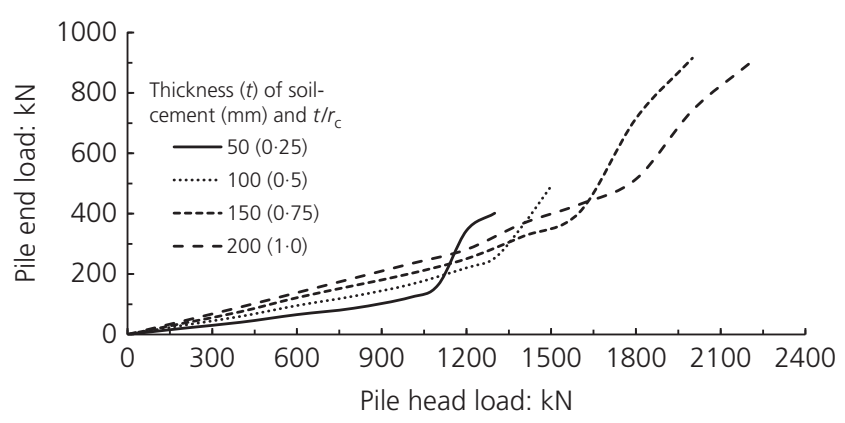

(b)

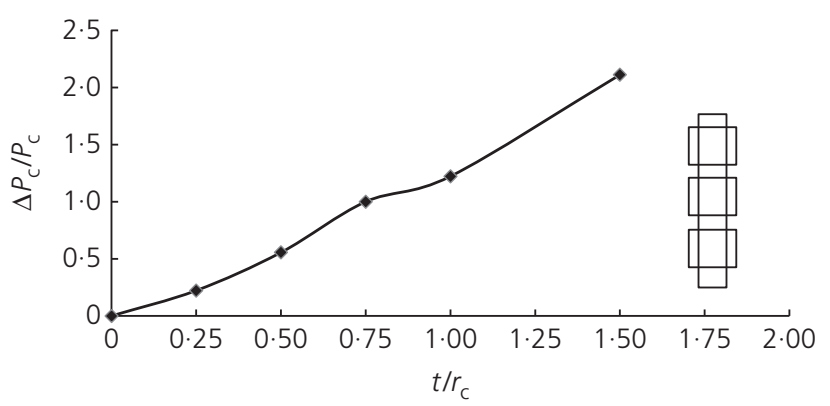

(c)

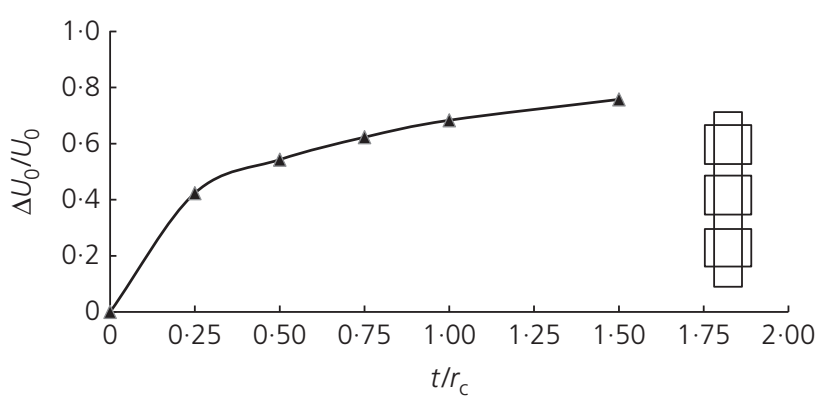

(d)

Figure 9. Soil-cement thickness for capacity and settlement: (a) pile head load-settlement curves; (b) base load-head load curves; (c) $t / r_{c}$ plotted against normalised gain in head capacity; (d) $t / r_{c}$ plotted against normalised reduction in pile head settlement

(see Figure 5(a)) requires $r_{\mathrm{x}} / r_{\mathrm{c}}<\tau_{\mathrm{cu}} / \tau_{\mathrm{xu}}$ (through $2 \pi r_{\mathrm{c}} \tau_{\mathrm{cu}} \Delta L>$ $\left.2 \pi r_{\mathrm{x}} \tau_{\mathrm{xu}} \Delta L\right)$, which leads to an upper bound of $r_{\mathrm{x}} / r_{\mathrm{c}}<10$ for $\tau_{\mathrm{cu}}=0.25 q_{\mathrm{u}}=0.25 \times 2000=500 \mathrm{kPa}$ and $\tau_{\mathrm{xu}}=50 \mathrm{kPa}$. This implies that the practice of using a soil-cement thickness of

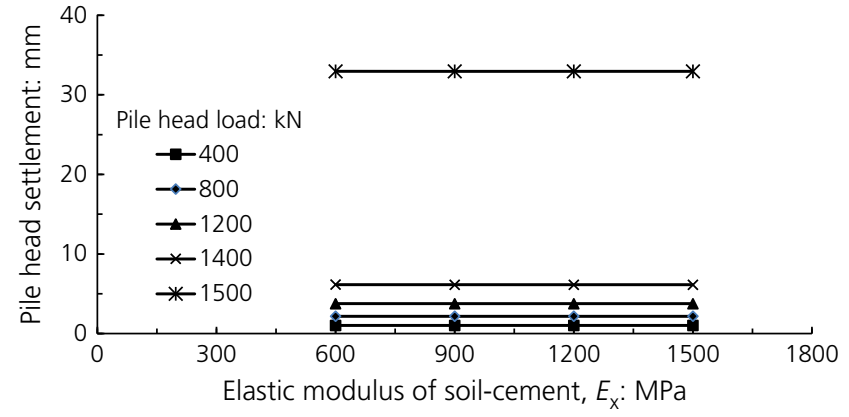

Figure 10. Pile head settlement for typical soil-cement modulus $E_{\mathrm{x}}$ (predicted for single JPP at different head loads)

$0 \cdot 1 \mathrm{~m}$ to $r_{\mathrm{c}}$ is good for curbing settlement and conservative for mobilising capacity.

\subsection{Soil-cement modulus $\left(E_{\mathrm{x}}\right)$ and shear stiffness ratio $\left(k_{\mathrm{c}} / k_{\mathrm{x}}\right)$}

Minimising the duration of construction is important and this may rely on the allowable degree of strength and stiffness (modulus) gain of the soil-cement. The pile head settlement of the three-segment JPP was obtained for a soil-cement modulus $\left(E_{\mathrm{x}}\right)$ of $0.6-1.5 \mathrm{GPa}$, at five typical load levels. As shown in Figure 10, the value of $E_{\mathrm{x}}$ had a negligible effect on the settlements at each load level and on the bearing capacity. This warrants proceeding with construction earlier, at a smaller modulus of $E_{\mathrm{x}}(0.6 \mathrm{GPa})$, and implies a negligible effect of $E_{\mathrm{x}}$ on the shearing stress between the soil-cement and the core pile.

It is difficult (if not costly) to determine exact values of the stiffness $k_{\mathrm{c}}$ (of the PC interface) and $k_{\mathrm{x}}$ (of the PS interface). The load-settlement curves (of a single three-segment JPP) were obtained for $\beta\left(=k_{\mathrm{c}} / k_{\mathrm{x}}\right)=10,100$ and 1000 . As shown in Figure 11, the value of $\beta$ barely affected the bearing capacity, and the low $\beta$ (of 10 ) induced a slightly higher settlement. The negligible effect of $\beta$ on the pile response is used as current practice requires $\beta>100$.

\subsection{Comments on JPP design}

The numerical simulations indicate that enhanced pile capacity comes from three-segment and full-length soil-cement and a thick soil-cement (and is insensitive to the soil-cement modulus and interface stiffness ratio $\beta$ ).

Further analysis provided the impact of segment length over the total length of soil-cement (i.e. $L_{\mathrm{S}} / L_{\mathrm{x}}$ ) on the capacity gain $\left(\Delta P_{\mathrm{c}}\right)$ over the ultimate bearing capacity of the core pile $\left(P_{\mathrm{c}}\right)$ and on the settlement reduction of the pile head $\left(\Delta U_{0}\right)$ from the settlement $U_{0}$ of the core pile at $P_{\mathrm{c}}$. The load ratio $\Delta P_{\mathrm{c}} / P_{\mathrm{c}}$ and displacement ratio $\Delta U_{0} / U_{0}$ are plotted against the normalised length $\left(L_{\mathrm{S}} / L_{\mathrm{x}}\right)$ in Figures $8(\mathrm{~d})$ and $8(\mathrm{e})$. These figures 


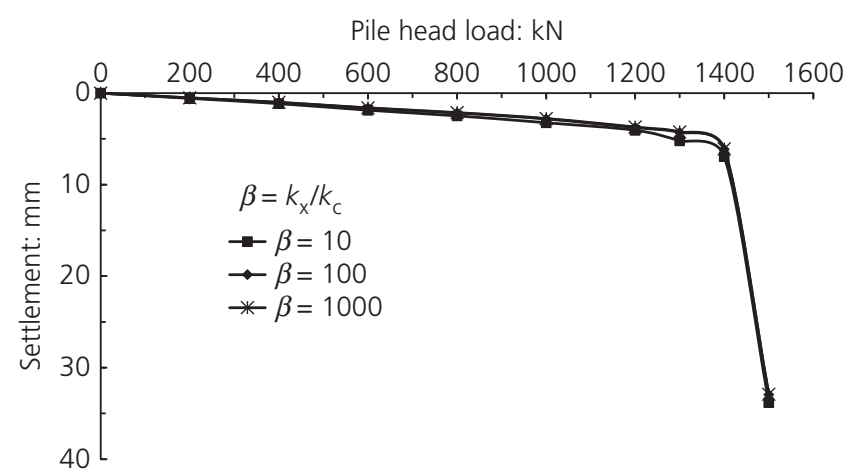

Figure 11. Load-settlement curves for different stiffness ratios $\beta$ (predicted for single three-segmented JPP) reveal that three short segments allowed up to $60 \%$ gain in the ultimate bearing capacity or $55 \%$ reduction in head settlement, while one or two long segment(s) enabled a $20-60 \%$ gain in capacity or a $43-52 \%$ reduction in head settlement. This further attests the benefits of using three segments over other layouts and one or two long segment(s) over conventional cast-in-place piles. The results also indicate that a thick soil-cement annulus $(t)$ raises the normalised capacity of $\Delta P_{\mathrm{c}} / P_{\mathrm{c}}$ (see Figure $\left.9(\mathrm{c})\right)$ and reduction in head settlement at $P_{\mathrm{c}}$ of $\Delta U_{0} / U_{0}$ (see Figure $9(\mathrm{~d})$ ) over the core pile. The settlement reduction in particular is four times more effective with $t / r_{\mathrm{c}}=0.25$ than otherwise.

The results of this study generally uphold the practice of using two to four segments around each JPP and a soil-cement thickness of $0 \cdot 5 r_{\mathrm{c}}-1 \cdot 0 r_{\mathrm{c}}$ (or $\left.r_{\mathrm{x}} \leq 1 \cdot 5 r_{\mathrm{c}}-2 \cdot 0 r_{\mathrm{c}}\right)$ and $r_{\mathrm{x}}-r_{\mathrm{c}} \geq 0 \cdot 1 \mathrm{~m}$.

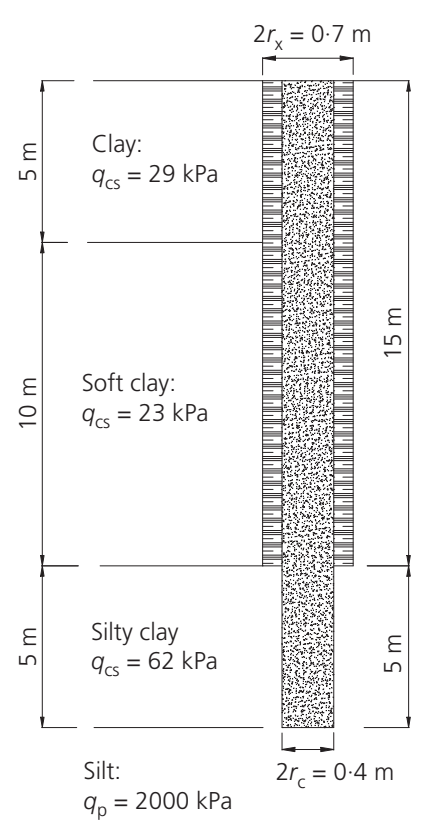

$\eta_{\mathrm{s}}=1 \cdot 35$

$Q_{u}($ calculated $)=1754 \mathrm{kN}$

$Q_{u}($ measured $)=1800 \mathrm{kN}$

Pile head load: $k N$

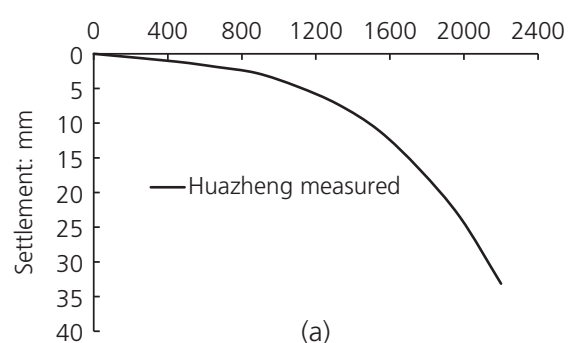

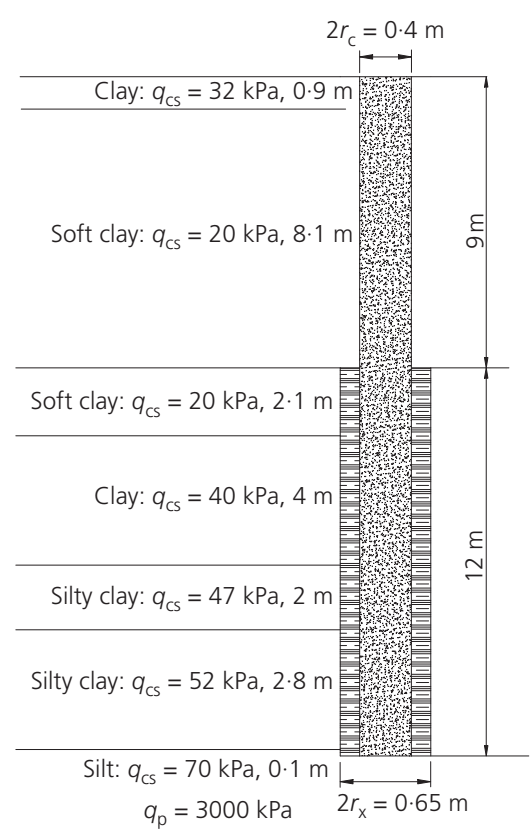

$\eta_{\mathrm{s}}=1 \cdot 5$

$Q_{u}($ calculated $)=2150 \mathrm{kN}$

$Q_{u}($ measured $)=2200 \mathrm{kN}$

Pile head load: kN

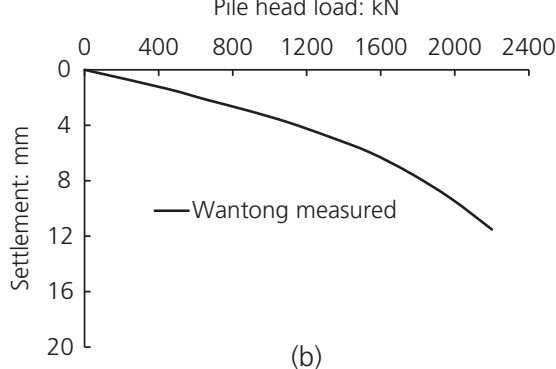

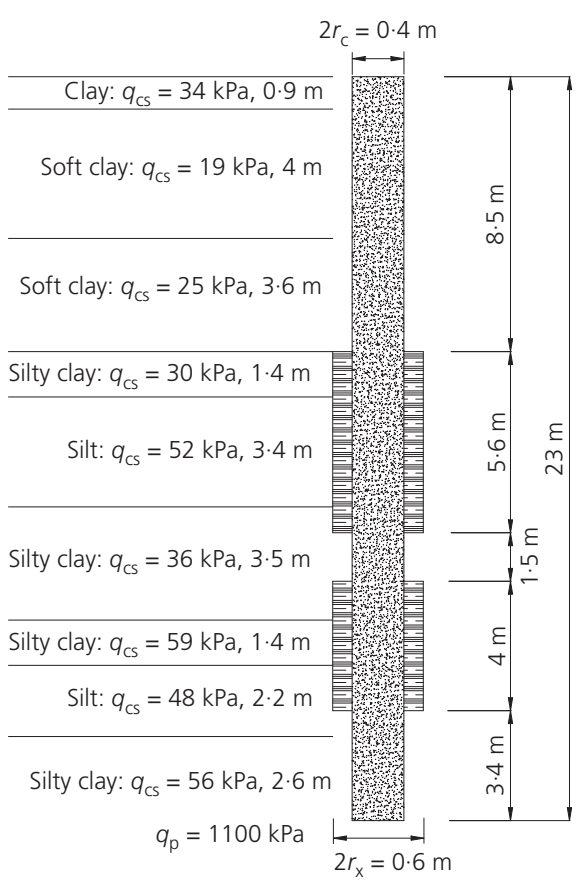

$\eta_{\mathrm{s}}=1 \cdot 4$

$Q_{u}($ calculated $)=1847 \mathrm{kN}$

$Q_{u}($ measured $)=1900 \mathrm{kN}$

Pile head load: $\mathrm{kN}$

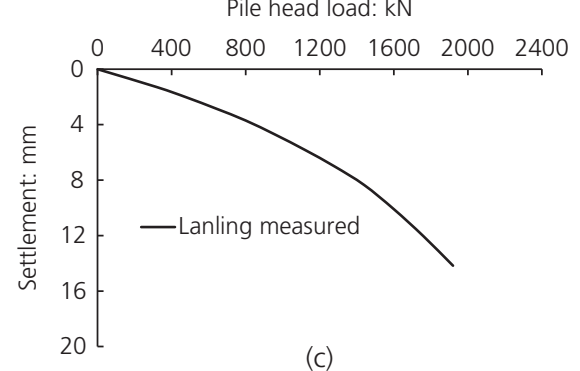

Figure 12. JPPs installed in three projects: (a) Huazheng office building; (b) Wantong building; (c) Lanling apartment (provided by Yuhua Lei, Huazheng Geotechnical Co., Ltd, Tianjin, China) 
Extra thickness beyond $0 \cdot 25 r_{\mathrm{c}}$ facilitates only $25 \%$ settlement reduction of a thinner cement wall, but it couples the core pile and soil-cement well (by controlling $q_{\mathrm{u}} \geq 2 \mathrm{MPa}$ and $\beta \geq 100$ ) and allows a continual increase in capacity.

The ultimate bearing capacity $\left(Q_{\mathrm{u}}\right)$ of a JPP may be pragmatically estimated using

$$
\text { 15. } Q_{\mathrm{u}}=u_{\mathrm{x}} \eta_{\mathrm{s}} \sum_{i=1}^{m} q_{\mathrm{cs} i} l_{\mathrm{x} i}+u_{\mathrm{c}} \sum_{j=1}^{n} q_{\mathrm{cs} j} l_{\mathrm{c} j}+q_{\mathrm{p}} A_{\mathrm{p}}
$$

in which $u_{\mathrm{x}}$ and $u_{\mathrm{c}}$ are the perimeters of the soil-cement and core pile, respectively, $q_{\mathrm{cs} i}\left(q_{\mathrm{cs} j}\right)$ and $q_{\mathrm{p}}$ are the ultimate shaft friction and base pressure of the core pile in the $i$ th $(j$ th) soil layer (see JGJ 94-2008 (MOHURD, 2008)), respectively, $m$ and $n$ are total numbers of soil layers in the zone of the soilcement and the core pile, respectively, $\eta_{\mathrm{s}}$ is the coefficient of shaft resistance, $1 \cdot 3-1 \cdot 7$, and $l_{x i}$ and $l_{\mathrm{c} j}$ are the lengths of soilcement in the $i$ th layer and the core pile in $j$ th layer, respectively.

Equation 15 offers slightly conservative capacities against the measured values (taking $\eta_{\mathrm{s}}=1 \cdot 35-1 \cdot 50$ ) for three typical projects (see Figure 12).

\section{Conclusions}

A simplified load-transfer approach to model the non-linear behaviour of a single JPP with expanded cross-sections at desired depth(s) has been presented. The approach is underpinned by three interface models (for interactions between two of the soil-cement, core pile and natural soil). The approach was compiled into an Excel program and was shown to produce good comparisons with the results of loading tests on two wellinstrumented JPPs. The proposed approach can readily accommodate layered soils and variable pile cross-sections. It captures the evolution of the pile response well, including distributions of axial force and displacement along pile and so on.

A parametric study revealed the following.

- One to three segments of thick soil-cement enable a $20-60 \%$ gain in bearing capacity and a $43-55 \%$ reduction in head settlement compared with a core pile without jet grouting; this was slightly affected by the modulus of the soil-cement wrapping and the stiffness ratio $\beta$ (of PC pile-cement and PS pile-soil interfaces).

- It is cost-effective to adopt two to four segments of soil-cement with a thickness of $0 \cdot 1 \mathrm{~m}$ to the radius of the core pile to produce an UCS for soil-cement of $>2 \mathrm{MPa}$ and a stiffness ratio $\beta>100$ to reduce settlement.

Finally, a simple expression was proposed to estimate the ultimate bearing capacity of a JPP. This equation was verified by comparing predictions from the equation with measured data of loading tests on JPPs in three case histories.

\section{Acknowledgements}

The authors would like to acknowledge the financial support of the National Natural Science Foundation of China (no. 51508166), the China Scholarship Foundation and the Key University Teacher Foundation of Henan Province (2015GGJS-243), the supply of loading test data from Tianjing Huazheng Geotechnical Engineering Co., Ltd and the inspirational collaborative support from the Centre for Geomechanics \& Railway Engineering, University of Wollongong, Australia.

\section{REFERENCES}

Ai ZY and Han J (2009) Boundary element analysis of axially loaded piles embedded in a multi-layered soil. Computers and Geotechnics 36(3): 427-434.

Cao W, Chen Y and Wolfe WE (2014) New load transfer hyperbolic model for pile-soil interface and negative skin friction on single piles embedded in soft soils. International Journal of Geomechanics 14(1): $92-100$.

Chen LZ, Liang GQ, Zhu JY and Ge W (1994) Analytical calculation of axial loading-settlement curve of piles. Chinese Journal of Geotechnical Engineering 16(6): 30-38 (in Chinese).

Comodromos EM, Papadopoulou MC and Rentzeperis IK (2009) Pile foundation analysis and design using experimental data and 3-D numerical analysis. Computers and Geotechnics 36(5): 819-836.

Guo WD and Randolph MF (1997) Vertically loaded piles in nonhomogeneous media. International Journal for Numerical and Analytical Methods in Geomechanics 21(8): 507-532.

Guo WD and Randolph MF (1998) Rationality of load transfer approach for pile analysis. Computers and Geotechnics 23(1): 85-112.

Guo WD and Randolph MF (1999) An efficient approach for settlement prediction of pile groups. Géotechnique 49(2): 161-179, http://dx.doi.org/10.1680/geot.1999.49.2.161.

Kraft LM Jr, Richard PR and Takaaki K (1981) Theoretical $\tau-z$ curves. Journal of Geotechnical Engineering 107(11): 1543-1561.

Lee KM and Xiao ZR (2001) A simplified method for nonlinear analysis of single piles in multilayered soils. Canadian Geotechnical Journal 38(5): 1063-1080.

Liu HL, Ren LW, Zheng H and Xiao YZ (2010) Full-scale model test on load transfer mechanism for jet grouting soil-cement-pile strengthened pile. Rock and Soil Mechanics 31(5): 1395-1401 (in Chinese).

Liu J, Xiao HB, Tang J and Li QS (2004) Analysis of load-transfer of single pile in layered soil. Computers and Geotechnics 31(2): 127-135.

Mandolini A and Viggiani C (1997) Settlement of piled foundations. Géotechnique 47(4): 791-816, http://dx.doi.org/10.1680/geot.1997. 47.4.791.

MOHURD (Ministry of Housing and Urban-Rural Development) (2008) JGJ 94-2008: Technical code for building pile foundations. MOHURD, Beijing, China.

Nanda S and Patra NR (2014) Theoretical load-transfer curves along piles considering soil nonlinearity. Journal of Geotechnical and Geoenvironmental Engineering 140(1): 91-101.

Randolph MF and Wroth CP (1978) Analysis of deformation of vertically loaded piles. Journal of Geotechnical Engineering 104(12): 1465-1488.

Randolph MF and Wroth CP (1979) An analysis of the vertical deformation of pile groups. Géotechnique 29(4): 423-439, http://dx.doi.org/10.1680/geot.1979.29.4.423.

Ren LW, Liu HL and Lei YH (2008) Technology and application of JG soil-cement pile strengthened pile. Chinese Journal of Geotechnical Engineering 30(s1): 518-522 (in Chinese). 
Ren LW, Liu XL and Wang GY (2010) Simplified calculation and analysis of load transfer behavior for single JPP. Chinese Journal of Rock Mechanics and Engineering 29(6): 1279-1287 (in Chinese).

Said I, Gennaro V D and Frank R (2009) Axisymmetric finite element analysis of pile loading tests. Computers and Geotechnics 36(1): 6-19.

Sheil BB and McCabe BA (2016) An analytical approach for the prediction of single pile and pile group behavior in clay. Computers and Geotechnics 75(5): 145-158.

Shen WY, Chow YK and Yong KY (1997) A variational approach for vertical deformation analysis of pile group. International Journal for Numerical and Analytical Methods in Geomechanics 21(11): $741-752$
Sheng D, Eigenbrod KD and Wriggers P (2005) Finite element analysis of pile installation using large-slip frictional contact. Computers and Geotechnics 32(1): 17-26.

Voottipruex P, Bergado DT, Suksawat T, Jamsawang P and Cheang W (2011) Behavior and simulation of deep cement mixing (DCM) and stiffened deep cement mixing (SDCM) piles under full scale loading. Soils and Foundations 51(2): 307-320.

Zhang QQ and Zhang ZM (2012) A simplified nonlinear approach for single pile settlement analysis. Canadian Geotechnical Journal 49(11): 1256-1266.

Zuo WL (2008) Test Study and Analysis of Bearing Behavior of Grouted Gravel Pile. PhD thesis, Hohai University, Nanjing, China (in Chinese).

\section{How can you contribute?}

To discuss this paper, please email up to 500 words to the editor at journals@ice.org.uk. Your contribution will be forwarded to the author(s) for a reply and, if considered appropriate by the editorial board, it will be published as discussion in a future issue of the journal.

Proceedings journals rely entirely on contributions from the civil engineering profession (and allied disciplines). Information about how to submit your paper online is available at www.icevirtuallibrary.com/page/authors, where you will also find detailed author guidelines. 